\section{The Wass report: moving forward 3 years on}

The editorial by Lawson and Kumar' on the lack of progress in implementing the recommendations of the 2016 Wass report is timely and welcome. ${ }^{2}$ We would like to highlight the response in Scotland. In early 2018, Scottish Government Health Workforce Directorate established a short-life working group on increasing undergraduate medical education in primary care. The membership comprised senior civil servants from Health Workforce, Primary Care and Health and Care Analysis, NHS Education Scotland, Scottish Funding Council, Undergraduate Deans, RCGP Scotland, Scottish GPs' Committee of the BMA, NHS Scotland Health Boards, medical students, and all GP Heads of Teaching (HoT) or equivalent in Scottish medical schools. This group was supported by an NHS Education Scotland group examining Additional Cost of Teaching (ACT) in primary care in Scotland.

The issue of funding for practices, as discussed in the editorial, was crucial. The methodology of Rosenthal et al ${ }^{3}$ was validated in Scottish practices, and a median figure of $85 \mathrm{GBP}$ per student per session was identified.

The final report - Undergraduate Medical Education in Scotland: Enabling More General Practice Based Teaching comprised 10 recommendations covering capital investment, improving digital access and connectivity, a rise in the tariff as set put above, growing the GP educator workforce, strengthening the leadership role of GP HoTs, and monitoring and research, and was published in October 2019.4 It was endorsed by the Board for Academic Medicine and supported by Ms Jeane Freeman, Cabinet Secretary for Health. ${ }^{5}$ Support includes the increase in funding for practices, which starts in April 2020.

This is an important step forward in Scotland. However, delivering on Professor Val Wass's report was always going to be challenging, and much remains to be done in Scotland and elsewhere. Evaluating the impact and monitoring the delivery of all 10 Scottish recommendations is under discussion but, of course, will have to await the resolution of the COVID-19 emergency.
John Gillies,

Chair, Increasing undergraduate education in primary care group; Honorary Professor of General Practice, University of Edinburgh. Email: john.gillies@ed.ac.uk

Maggie Bartlett,

Chair of Education in General Practice, University of Dundee.

Jon Dowell,

Scottish Graduate Entry Medicine

(ScotGEM) Programme Director, University of Dundee.

Karen Fairhurst,

Director Year 4, University of Edinburgh Medical School, University of Edinburgh.

Ken Lawton,

Deputy Head of GP and Community Medical Education, University of Aberdeen.

Lindsey Pope,

Director of Community Based Medical Education and Deputy Director, Scottish School of Primary Care, University of Glasgow.

Rebecca Walmsley,

Acting Course Director, Clinical

Programme Lead, University of St Andrews.

\section{REFERENCES}

1. Lawson E, Kumar S. The Wass report: moving forward 3 years on. Br J Gen Pract 2020. DOI: https://doi.org/10.3399/bjgp20X708953.

2. Wass VJ, Gregory S, Petty-Saphon K. By choice - not by chance: supporting medical students towards future careers in general practice. 2016. https://www.hee.nhs.uk/sites/default/files/ documents/By\%20choice\%20-\%20not\%20by\%20 chance.pdf (accessed 16 Apr 2020)

3. Rosenthal J, McKinley RK, Smyth C, Campbell $\mathrm{JL}$. The real costs of teaching medical students in general practice: a cost-collection survey of teaching practices across England. Br J Gen Pract 2020; DOI: https://doi.org/10.3399/bjgp19X706553.

4. Scottish Government. Undergraduate medical education in Scotland: enabling more general practice based teaching. 2019. https://www. gov.scot/publications/undergraduate-medicaleducation-scotland-enabling-more-generalpractice-based-teaching/pages/11 laccessed 16 Apr 2020).
5. Scottish Government. Growing the next generation of GPS. 2019. https://uww.gov.scot/news/growing-thenext-generation-of-gps laccessed 16 April 2020)

\section{Video consultations in UK primary care in response to the COVID-19 pandemic}

The COVID-19 pandemic has necessitated a rapid response from UK primary care services and has prompted practices to consider implementing alternative methods of remote consultation to minimise faceto-face visits. The recent guidance from Greenhalgh and colleagues ${ }^{1}$ regarding the use of video consultations in primary care is therefore timely and has important practical implications.

The guidance offers a useful summary of situations in which video consultations may be appropriate for either 'COVID-related' or 'non-COVID-related' consultations and provides tips on which patients may not be suitable for video consultations. The authors also outline the steps involved in setting up a video consultation service and provide advice on how to perform an effective video consultation.

What is apparent from reading the guidance and its associated $B M J$ article $^{2}$ is that there is a paucity of high-quality data regarding the efficacy and safety of video consultations in primary care, particularly in the context of acutely unwell patients. An area that warrants further research is the utility of video consultations for remotely performing physical examinations. Moreover, the relative advantages and disadvantages of video versus telephone e-consultations remain unclear. ${ }^{3}$

However, given the exceptional circumstances we find ourselves in, it is our view that implementation of technology to facilitate alternative methods of remote consultation, including video consultations, needs to happen urgently to enable primary care practitioners to provide ongoing care to patients who are unable to attend in person. 